\title{
Factors Underlying Current Saudi EFL Teachers' Approaches to Teaching the Four Macro and Micro Language Skills
}

\author{
Khalid Al-Seghayer ${ }^{1}$ \\ ${ }^{1}$ College of Languages and Translation, Al Imam Mohammad Ibn Saud Islamic University, Riyadh, Saudi Arabia \\ Correspondence: Khalid Al-Seghayer, College of Languages and Translation, Al Imam Mohammad Ibn Saud \\ Islamic University, Riyadh, Saudi Arabia. E-mail: alseghayer@yahoo.com
}

\author{
Received: July 8, $2021 \quad$ Accepted: August 14, $2021 \quad$ Online Published: August 19, 2021 \\ doi:10.5539/ijel.v11n5p44 URL: https://doi.org/10.5539/ijel.v11n5p44
}

\begin{abstract}
A close examination of the underlying pedagogical and related factors that shape and direct English as a foreign language (EFL) teachers' instructional approaches and behaviors highlights the impossibility of teaching the core and language skills and language-related areas effectively when using the current outdated techniques. The purpose of this article is to orient the reader and succinctly identify the key factors underlying current Saudi EFL teachers' approaches to teaching the four macro and micro language skills. It delineates the various factors that influence the current EFL teaching process in the Saudi English education system, along with briefly sketching Saudi EFL teachers' approaches to teaching each language skill. To this end, this discussion contributes to increasing consciousness of factors that affect the actual pedagogy of EFL teachers in Saudi EFL classrooms and perhaps to encouraging Saudi EFL teachers to exert their effectiveness in Saudi EFL classrooms and strive for better performance.
\end{abstract}

Keywords: pedagogical factors, instructional approaches, Saudi EFL teachers, four language macro skills, micro language skills

\section{Introduction}

Factors that contribute to and influence instructional practices in English as a foreign language (EFL) classrooms are essential concerns in the EFL-teaching profession and require thoughtful attention. This importance stems from the fact that underlying pedagogical factors determine the nature of teaching practices in an EFL classroom and exert significant constructive or adverse influences on the implementation of a variety of classroom EFL-teaching practices. Furthermore, recognizing and closely examining these factors will allow practitioners to obtain a far better understanding of EFL classroom instructional practices and performance and ultimately will improve the EFL-teaching process. These factors vary by EFL context; as such, fruitful exploration will be gained by examining each EFL context closely and individually to reveal the genuine factors affecting current instructional practices in the designated EFL classrooms.

In the Saudi EFL context, the four macro language skills—listening, speaking, reading, and writing —along with specific micro or language-related skills (namely, grammar, vocabulary, and culture) are integrated consecutively into each 45-minute class period; each skill is allotted a designated portion of the class period, four times a week. Therefore, the practices that permeate Saudi EFL classes are based largely upon the integrated process of learning a foreign language being reduced into subsets of discrete skills and areas of knowledge, with each skill and area being taught in isolation. As frontline players and the essential components of the EFL teaching process in the Saudi EFL education system, Saudi EFL teachers are the developers and implementers of instructional practices in Saudi EFL classrooms. The teachers' instructional function is to deliver instruction effectively, which is influenced by a myriad of complex contextual underlying factors informing their current approaches to teaching the four major and three related language skills in Saudi EFL classrooms that are indispensable parts of the English curriculum.

To this end, this work presents a close examination of the implemented modalities of EFL pedagogical practices and their distinct features, in order to identify the key factors underlying current Saudi EFL teachers' approaches to teaching the four macro and micro language skills. Each of the seven sections of the present article is divided into two parts. The first part opens with an overview that introduces and briefly explains the main dimensions of the language skill or language-related skill at hand. Specifically, this part begins by summarizing the features of 
the actual instructional practices in Saudi EFL classrooms regarding one of the four macro language skills or a language-related skill. The second part elucidates the reality of the skill's actual instructional implementation and determines the specific causes behind the current pedagogical instruction for each individual language skill that eventually harm teachers' pedagogical practices and classroom performance. Consequently, the actual pedagogy of EFL teachers in Saudi classrooms fails to be coordinated effectively.

This article will hopefully inform prospective Saudi EFL teachers about and encourage them to consider several key counterproductive pedagogy-related factors (i.e., primarily those related to the exacerbated and long-existing application of the current outmoded language teaching approaches, namely the grammar-translation and audio-lingual methods) that influence the prevalence of current instructional practices in the Saudi EFL context and accordingly develop skills for adaptability.

\section{Current Approaches to Teaching Listening Skills}

\subsection{Overview of Saudi EFL Teachers' Approaches to Teaching Listening Skills}

Within the Saudi EFL context, listening skills rarely have been deemed worthy of serious pedagogical attention. During listening classes, Saudi EFL teachers employ instructional approaches that favor the development of bottom-up skills, primarily to aid students with lower English proficiency who must expand their language skills. Teachers conduct bottom-up listening exercises and tasks designed to promote students' mastery of discrete skills or microskills related to listening comprehension, such as recognizing lexical, grammatical, and pronunciation features and language forms at the word and sentence levels as well as discriminating English pronunciation, stress, intonation, and language flow. They tend to train students to develop these microskills through repetition. Thus, Saudi EFL teachers fail to recognize the need for developing students' functional listening comprehension skills.

Focusing on bottom-up processing skills, teachers ask students to distinguish individual sounds, recognize word boundaries and stressed syllables, listen for intonation patterns and specific details, identify grammatical forms and functions, recognize contractions and connected speech, manipulate sounds when playing with words (such as by adding or removing sounds), and recognize linking words and phoneme sequences as students circle the words they hear. Other popular traditional listening activities that are focused primarily on bottom-up processing include dictation, cloze listening, identification of key words in a text, text-based multiple-choice questions, segmentation of words into syllables and sounds, identification of answers from listening materials, and other similar activities that require close and detailed recognition and input processing.

Unlike teachers in process-oriented classrooms, Saudi EFL teachers are in total control of classroom activities (Al-Sobhi \& Preece, 2018). To teach specific, isolated listening skills, they select inputs, design and sequence listening activities, determine tasks, and decide what constitutes a correct response. However, Saudi teachers focus more on testing students' listening abilities than on helping them to cultivate their listening skills by teaching them effective listening-comprehension strategies (Jamal et al., 2020). In this case, typical listening instruction goes through the following cycle: students listen to a text, they answer questions based on the text, and the teacher shares the correct answers. Beyond exposing students to listening segments, this teaching cycle does not develop students' listening skills or help them learn listening strategies. In this way, actual practice reflects traditional methods of listening instruction, in which listening skills are tested but not really taught. Thus, there is a virtual exclusion of teaching listening skills. Jamal et al. (2020) stated that teaching of listening skills in Saudi English classrooms is limited to completing assessment activities, without providing sufficient exposure to comprehensible input.

Additionally, Saudi EFL teachers do not implement the pedagogical sequence of pre-listening, listening, and post-listening activities. If used consistently and sequentially, these activities can guide students through the necessary mental processes for successful listening comprehension and promote the acquisition of metacognitive strategies. Likewise, teachers do not introduce activities that link bottom-up (in which the listener attends to data in the incoming speech signals) with top-down listening (in which the listener utilizes prior knowledge and expectations to guide the understanding process).

Overall, Saudi EFL teachers do not consider students' listening-comprehension problems or focus on the processes and skills through which listening takes place. These failures are linked to teacher training. For example, in Hamouda's (2013) study, 83.3\% of Saudi English teachers surveyed indicated they had not received sufficient training in English listening comprehension during their college education. Moreover, $81.7 \%$ had never heard about listening strategies. 


\subsection{Factors Underlying Current Saudi EFL Teachers' Approaches to Teaching Listening Skills in Saudi EFL Classrooms}

Several factors influence the prevalence of these instructional practices in the Saudi EFL context. First, According to Nurul Islam (2012) and Hamouda (2013), listening is the least understood aspect of language teaching in Saudi EFL classrooms. Therefore, listening skills are neglected, and Saudi teachers tend to overlook their importance in language learning because such skills have no immediate observable output. Bano (2017) and Mohamed (2018) argued that listening skills are neglected in teaching and are the most disregarded of the four skills in Saudi English classrooms. Moreover, teachers pay limited attention to developing listening skills when designing their lessons, perhaps because they assume students will develop listening comprehension naturally in the language-learning process. Accordingly, despite an increased focus on teaching other language skills, the time and resources allocated to developing students' listening abilities remain inadequate in Saudi EFL education. Precisely, little class time is devoted to developing any elements beyond the most basic of listening skills (Al-Bargi, 2013; Al-Seghayer, 2019). Therefore, although listening skills are crucial in language acquisition, these skills lag behind others in current teaching practice because they are not taught in a separate mode in the Saudi EFL context.

Second, the current listening instructional practices overuse two activities: (a) students listening to spoken text and answering comprehension questions afterward as the ultimate instructional goal and (b) Saudi EFL teachers engaging students in listening activities that focus on retrieving information from long-term memory, rather than on the processing activities themselves. Such activities might include listening to a passage and responding to true-or-false questions at the end, which place the focus on the outcome of listening instead of on the listening process itself.

Third, Al-Seghayer (2017) contended that Saudi EFL teachers are uncertain about how best to teach listening skills. They teach micro skills related to listening comprehension, such as the discrimination of English pronunciation, stress, intonation, and language flow, and train students to develop these micro skills through repetition. However, these teachers fail to recognize the need to develop students' functional listening-comprehension skills.

Fourth, Saudi EFL teachers do not base their listening instruction on theoretical principles and are unaware of relevant theories or the fact that listening is a complex mental process that involves perception, attention, cognition, and memory. They fail to comprehend that listeners are involved in a dynamic construction of meaning, in which oral input is understood through sound discrimination, prior vocabulary knowledge, discrimination of differences in word order and grammatical form, changes in stress and intonation, tone placements, phonological rules, and nonlinguistic clues in contextual utterances. These teachers also seem incapable of training students to use various listening strategies or helping them to acquire useful tools with which to improve their English listening competence.

Fifth, the instructional time and resources (such as well-equipped English digital-listening laboratories; cassette tapes, CDs, or audio files; tape recorders; written listening texts; and other helpful technical tools) allocated for developing students' listening abilities remain inadequate (Alsowat, 2017; Al-Sobhi \& Preece, 2018; Panduranga, 2016). Therefore, Saudi EFL students are insufficiently exposed to English and lack apparatuses and listening materials that are appropriate for their grade levels and individual needs. On this note, $74 \%$ of the Saudi EFL teachers in Almalki's (2014) study indicated that they only used methodologies that were consistent with the time available for teaching each lesson.

\section{Current Approaches to Teaching Speaking Skills}

\subsection{Overview of Saudi EFL Teachers' Approaches to Teaching Speaking Skills}

Teachers in Saudi EFL classes use various approaches and techniques to teach speaking skills, including direct approaches that focus on specific features of oral interaction (such as turn taking, topic management, and questioning strategies) and drill- or repetition-based methodologies (such as repeating after the teacher, memorizing a dialogue, responding to drills, and answering questions). However, none of these traditional methods, rooted in 1970s pedagogy, simulates real interactions or engage students in meaningful speaking activities that would prepare them for fruitful, constructive, real-life interactions. Instead, these methods simply require students to repeat phrases verbatim and, as a result, fail to support the development of essential oral skills and communication strategies.

The teaching strategies currently used in Saudi EFL classrooms, which reflect the sentence-based view of proficiency prevalent in outdated audiolingual and other drill- or repetition-based methodologies, do not provide 
opportunities for students to acquire each type of speaking skill. Additionally, these teaching techniques do not include different meaningful speaking activities such as role-playing, jigsaw tasks, conversations, group discussions, information gaps, or other game activities. They also, as indicated by Al-Seghayer (2015), do not incorporate interactive tasks such as interviewing, storytelling, making small talk, ending conversations, narrating and describing pictures, reacting to what others are saying, discussing cultural topics, or recounting personal incidents and experiences. Additionally, they do not incorporate communicative language-teaching principles. Moreover, teachers do not engage their students in tasks such as asking and answering questions in class, giving in-class presentations, or working together in groups (Al-Saraj, 2014). Accordingly, Saudi EFL students are neither engaged in real speaking environments nor introduced to environments that would encourage them to practice speaking in context.

\subsection{Factors Underlying Current Saudi EFL Teachers' Approaches to Teaching Speaking Skills in Saudi EFL Classrooms}

Several factors influence current speaking instructional practices in Saudi classrooms. First, as noted in the features overview of Saudi EFL teaching, many EFL teachers allow students to use Arabic in the classroom (Hamad, 2013). In Abu-Ghararah's (2014) study, 80\% of participants indicated that they mostly used Arabic with their English teachers during class time. Similarly, about 70\% of the EFL teachers observed by Al-Ma'shy (2011) did not encourage their students to speak English in the classroom or use different speaking activities, and $80 \%$ interacted with their students in Arabic. Because of this preference among teachers for Arabic, Saudi students lack opportunities to practice speaking English in the classroom; simultaneously, speaking activities are limited to reading a text or answering the teacher's questions (Abu-Ghararah, 2014). Similarly, Kashmiri (2019) explored the challenges faced by 66 Saudi EFL learners as they attempted to formulate strategies to overcome their speaking difficulties. The findings reveal that Saudi EFL teachers are the cause, by allowing their students to interact in Arabic during speaking activities. Furthermore, teachers also use traditional methods when teaching speaking skills. Similarly, Naser and Hamzah (2018) investigated the pronunciation and conversation difficulties faced by Saudi EFL learners and found that the teachers employing archaic speaking teaching methods was among the reasons leading to speaking difficulties.

Saudi EFL teachers also do not encourage students to express their opinions in English. Instead, they tend to ask display questions (Al-Zahrani \& Al-Bargi, 2017), rather than referential questions or questions seeking open-ended answers, thereby hindering students' opportunities for negotiated interaction. For example, in a study on assessing oral proficiency in large EFL classrooms in Saudi Arabia, Al-Shabeeh (2014) observed two 10th-grade classes and found that Saudi EFL teachers used no referential questions but posed 19 and 26 display questions, respectively; the 12th-grade class observed in the same study was asked five referential questions and 19 display questions.

Unlike referential questions, which trigger longer answers and increase participants' willingness to participate, display - or close-ended - questions are used to check and confirm students' comprehension, reflecting the question-answer-evaluation model. Accordingly, display questions do not provide opportunities for students to practice authentic communication or permit other possible meanings that students might contribute to the classroom discourse (Al-Hamdan, 2014). Moreover, this approach restricts students' involvement in classroom discussions and discourages them from communicating among themselves in English during class time.

Third, students receive very limited opportunities to speak English, and the time devoted to speaking in class is insufficient. Students study English for only 4 hours per week, during which they study listening, speaking, reading, and writing skills integratively. Thus, speaking skills do not get their due share of attention in Saudi EFL classrooms. According to Nather (2014), of the 756 hours of English instruction students receive over 9 years of study, students only complete approximately 160 hours (21\%) of English-speaking instruction. Furthermore, in Sharma's (2015) study, $80 \%$ of the participating students stated that they were not given any opportunities to speak in English in class.

Fourth, Saudi EFL classes are relatively large, with more than 40 students in each class, and the heavily loaded English syllabi incorporate insufficient speaking activities. In such situations, Saudi EFL teachers find it difficult to set up speaking activities, monitor students, give feedback, and get students to speak.

Fifth, offering a true reflection of a teacher-centered methodology and student passivity in the classroom, Saudi EFL teachers tend to speak for most of the class time, while students mumble and swallow their words. This teacher-centered approach severely limits students' opportunities to interact and participate in class or even complete a minimum of English-speaking practice. Thus, students in Saudi EFL classrooms act as mere receptors, memorizers, and reproducers (Al Rabai, 2014). Accordingly, as Abu-Ghararah (2014) found, Saudi students 
rarely practice speaking English in the English classroom, and speaking activities are limited to reading a text or answering the teacher's questions. Similarly, the findings showed that participants were given minimal chances to practice English and that most classes were teacher-centered. One might link this approach to Saudi academic culture, wherein teachers dominate the learning process and students are passive observers.

Sixth, as previously noted, Saudi speaking classes do not include classroom speaking activities or tasks such as role-playing, debates, discussions, presentations, cultural debate topics, or pair-speaking activities. Moreover, in the previously cited study on oral proficiency assessment in large EFL classrooms, Al-Shabeeh (2014) observed that classroom interaction mostly involved one-way interactions initiated and maintained by ESL teachers. On this note, approximately $70 \%$ of the 245 students Al-Shabeeh surveyed reported that they spent their class time listening to instruction delivered by the teacher. Al-Shabeeh also noted that student interaction was limited to task completion and did not include meaning negotiation.

Seventh, Saudi EFL teachers do not use contemporary speaking techniques in the classroom to develop students' speaking skills. According to Al-Harbi (2015), Saudi EFL classes devote a significant amount of time to learning and memorizing language forms, at the expense of teaching speaking skills. Saudi students are also not required to engage in tasks such as asking and answering questions in class, giving in-class presentations, or working together in groups (Al-Saraj, 2014). This situation may result from the teacher lacking training and knowledge concerning conversational analysis or the analysis of real speech. However, Nather (2014), who explored the effects of implementing Let's Speak English $(L S E)$ program in a seventh-grade Saudi English-speaking classroom, found that Saudi EFL teachers view speaking activities as boring, time consuming, and less important.

Finally, various additional factors influence the direction of Saudi EFL speaking instruction, such as the fact that traditional classroom-speaking practices, particularly drills in which one person poses a question and another responds, still dominate Saudi English classrooms (Sharma, 2015). Additionally, Saudi students' speaking skills are rarely tested, oral group work is rarely undertaken, cooperative learning activities are scarce, feedback is rarely given, and meaning negotiation does not occur.

All of the reasons identified above found support in the study of Bani Younes and Al-Balawi (2016), who investigated the factors leading to speaking difficulties among Saudi EFL students. The results revealed that a number of factors affect Saudi EFL students' speaking performance. These difficulties include a lack of conceptual knowledge, low participation during class time, lack of teacher feedback during speaking activities, anxiety, preference for using Arabic during English classes, insufficient time for speaking activities, and students' lack of confidence while speaking English during class activities. Many students may be reluctant to speak in English in front of their classmates because doing so can be extremely face threatening.

\section{Current Approaches to Teaching Reading Skills}

\subsection{Overview of Saudi EFL Teachers' Approaches to Teaching Reading Skills}

Saudi EFL teachers also struggle to teach English reading skills and precise reading comprehension adequately (Al-Abiky, 2014; Masadeh, 2015). According to Hazaea and Alzubi (2016), in Saudi English reading classes, teachers direct the reading process, and students generally are passive or marginalized. According to Al-Shumaimeri (2011), Al-Nooh (2013), and Al-Seghayer (2015) oral reading is the most preferred reading method among Saudi English teachers. Reading aloud, wherein students read a text to the rest of the class, occupies a major portion of the teaching time. Instructors may stop students occasionally to correct their pronunciation or to ask about the meaning of individual words they have read. Alternatively, the teacher may read aloud while the students follow the text in their books as a whole class, in groups, in pairs, or individually.

Furthermore, Al-Samadani (2012) found that Saudi EFL teachers devoted the designated class time to reading, practicing silent reading, and answering reading-comprehension questions, at the expense of teaching and practicing reading skills and strategies. Thus, the instructional practice for reading lacks reading-comprehension instruction and is in an initiation-response-evaluation format (i.e., students read silently, the teacher asks questions, students respond, and the teacher evaluates whether the response is correct or incorrect). Thus, students merely are able to perform short-answer questions and literal recalls but fail to demonstrate the ability to infer and make connections among text ideas due to the little attention given to comprehension, as opposed to the greater attention given to reading aloud. On this note, $75 \%$ of the EFL teachers Al-Samadani surveyed indicated they knew nothing about metacognitive reading strategies. Although they were aware of cognitive reading strategies, they tended to avoid teaching these strategies because doing so would require tremendous effort and time, and, as Al-Nooh (2013) noted, 45 minutes of class time is not enough to teach L2 reading skills. Thus, reading instruction in Saudi schools generally entails oral repetition of passages and a literal level of 
comprehension (Al-Samadani, 2011). However, such practices clearly demonstrate that Saudi EFL teachers are not fully aware of their roles in teaching L2 reading or even of what reading comprehension involves. Unfortunately, much of the reading instruction that takes place inside the classroom is test-driven instruction generally geared toward passing final exams.

Other common strategies used in Saudi EFL classrooms include scanning the text; reading the text aloud; explaining vocabulary items; translating words, phrases, or clauses into Arabic; asking questions to check comprehension; and teaching students to guess the meaning of ambiguous vocabulary (Bamanger \& Gashan, 2014). The EFL teachers in Bamanger and Gashan's (2014) study asserted that these were the most significant strategies in teaching reading skills to Saudi EFL students. In contrast, the EFL teachers in Al-Rojaie's (2011) study favored oral reading instruction and decoding passages word by word, but they did not implement reading strategies such as detecting main ideas, activating students' prior knowledge, summarizing and retelling, or monitoring reading comprehension.

Overall, in a study examining the performance of Saudi English reading teachers with reference to the processes, procedures, or techniques they employ in English reading classes, Masadeh (2015) found that Saudi EFL teachers (a) consider reading as the decoding of words into speech and as students reading isolated words, instead of making sense of the text; (b) do not equally distribute reading activities between bottom-up and top-down skills, and (c) are not successful in leading productive reading discussions, particularly due to their misconceptions of the questions for text discussion and the timing of the questions asked.

\subsection{Factors Underlying Current Saudi EFL Teachers' Approaches to Teaching Reading Skills in Saudi EFL Classrooms}

Various contextual factors and challenges inform current instructional practices for EFL reading in Saudi Arabia. First, Saudi EFL students exhibit a lower level of reading proficiency due to (a) weak linguistic knowledge (such as of L2 culture, syntax, semantics, phonology, morphology, and orthography), metalinguistic knowledge, and discourse knowledge; (b) poor reading skills and underachievement in the classroom; (c) ineffective reading habits and lack of interest in reading English texts; (d) limited vocabulary knowledge; and (e) deficient functioning of both lower- and higher-level processing skills. For example, Rajab and Al-Sadi (2015) found a low tendency among Saudi EFL learners to read English texts. When asked if they had ever read a story or book in English, 304 out of 330 students surveyed responded "no." Similarly, Al-Qahtani (2016) found that 63\% of participating students had not read English texts. Such attitudes toward reading English texts, as Al-Subaie's (2014) study showed, mainly are attributable to the Saudi cultural norms for reading, in that no reading habit are commonly established in any level of Saudi society. Neither families nor schools emphasize the importance of reading for pleasure, and no role models exist for reading in public. Al-Seghayer (2019) contended that reading English texts is a formidable task for Saudi EFL learners, who lack reading motivation and have little interest in reading English texts.

Second, as previously noted, time constraints are a major barrier to the implementation of effective and efficient pedagogical reading practices (Keezhatta \& Omar, 2019). During class time (45 minutes), teachers are busy maintaining discipline, organizing materials, checking homework and attendance, and explaining questions and concepts. Thus, students do not spend enough time practicing reading skills such as of comprehending, interpreting, inferring, integrating, criticizing, analyzing, connecting, and evaluating ideas in texts. Moreover, reading instruction lacks cooperative learning activities such as well-planned and supervised pair work, small group work, and peer teaching to promote creativity, scaffold confidence, promote positive attitudes toward reading English, and facilitate comprehension.

Third, classrooms lack appropriate supporting materials, reading topics are unfamiliar and unsuitable, and textbooks often contain insufficient reading activities that do not teach reading skills. Saudi teachers also do not know how to create supplementary materials or activities. The English teachers who participated in Al-Qahtani's (2016) study emphasized that the current English textbooks contained insufficient reading activities and unfamiliar topics that did not emphasize reading skills.

Fourth, Saudi EFL teachers' own experiences of learning EFL significantly influence their reading instructional practices. Accordingly, these teachers overlook the prerequisite subcomponent skills underlying the nature of reading in relation to English. The six English supervisors whom Al-Qahtani (2016) interviewed stressed that Saudi English students' reading skills are extremely poor because teachers devote insufficient attention to enhancing students' reading-comprehension skills in both careful and expeditious types of reading. Saudi instruction also lacks appropriate reading stages and activities. Most instructors involve literal comprehension skills at the sentence level, such as word recognition, and teachers' instructional focus primarily is on teaching 
students strategies to answer comprehension questions because these teachers are poorly trained in reading-comprehension abilities with which to implement effective teaching reading methods in general.

Fifth, Saudi EFL students lack sufficient in-class reading practice, specifically with reference to primary reading tasks (analyzing reading texts by identifying details, uncovering main ideas, and making inferences on implied text information) and secondary types of reading tasks or subskills such as fluency (the ability to read with ease and automaticity), the use of schemata, awareness of text structure, vocabulary, and training in readingcomprehension skills. Al-Subaie (2014) explored the nature of reading comprehension challenges faced by Saudi EFL learners and found that the participating Saudi EFL students exhibited poor reading comprehension due to a lack of sufficient reading practice during class time.

Sixth, Saudi EFL teachers do not differentiate between the two types of theoretical orientations to reading instruction - that is, between competence-based and text-based orientations to reading instruction. A text-based orientation is a theoretical orientation to reading instruction that emphasizes in-depth explication of texts and their constituents, including of words, content, and rhetorical usage. A competence-based orientation to reading instruction focuses on the learners' skill development through student-directed activities and comprehension strategies.

Seventh, Saudi EFL teachers are less aware of theoretical orientations toward L2 reading, reading processes, and the integration of theory into actual EFL reading instruction. Additionally, they are not well aware of the three categories of factors that affect comprehension: factors in the reader (interest/motivation, fluency, and metacognition); factors in the text (concept density, organization, and style); and readability (length of the sentences and difficulty of the vocabulary). On this note, Al-Qahtani (2016) contended that Saudi EFL teachers lack the proper training to implement effective teaching methods for English reading and possess insufficient knowledge about reading skills and how to promote them. They also lack the linguistic competence necessary to use innovative reading strategies and activities, and they demonstrate an insufficient knowledge of systematic vocabulary instruction, relevant reading strategies, and ways to implement them effectively in the classroom. Accordingly, Saudi teachers lack knowledge on how to teach reading strategies, create supplementary materials and activities, or assess their students' learning.

In sum, Saudi EFL teachers pay little attention to comprehension and more attention to reading aloud. It is not uncommon to see a Saudi EFL student who reads aloud beautifully but cannot understand what they have read. They are doing great "word calling," but this is not reading. In addition, Saudi EFL teachers do not know enough about theoretical and pedagogical issues related to L2 reading comprehension and instruction, such as the nature of automatic versus strategic reading, metacognition or strategic competence, human information processing (theoretical issues), or strategic reading-instruction studies and strategic reading-instruction models that promote strategic reading competence and learning strategies (pedagogical issues). The findings of two studies confirmed the above causes for the current reading instruction in English classrooms. Masadeh (2015) explored how Saudi English teachers perceive reading and comprehension. The results also showed that only $40 \%$ of the surveyed Saudi EFL teachers were aware of the main actions and steps that must be implemented in the classroom for reading comprehension. In particular, $17 \%$ of the male and $27 \%$ of the female teachers who participated in the study did not look for the main aim of the reading text under study, and only $10 \%$ of the male and $15 \%$ of the female teachers could differentiate between bottom-up and top-down reading processes. With respect to eliciting ideas, only $13 \%$ of the male and $12 \%$ of the female teachers encouraged students to identify the text's ideas themselves. Additionally, the teachers generally spent class time on teaching unknown lexes, asking students to read the text silently, asking short questions about the text, reading a text aloud in front of students, asking students to read a text aloud one by one, and asking comprehension questions, all of which can be classified as unhelpful instructional activities for reading that would not lead to effective or useful results. This shows a lack of reading-comprehension instruction in Saudi English reading classrooms. Moreover, teachers engage their students in comprehension tasks, rather than explicitly training them to use strategies to enhance their reading comprehension. These blunders and vague reading activities, along with the demonstrated results, indicate that Saudi English teachers clearly suffer from severe deficiencies in managing reading lessons effectively.

Likewise, the findings of Al-Qahtani's (2016) study, which investigated the reasons behind Saudi learners' poor reading skills, demonstrated that their English reading practice lacked appropriate reading stages and activities and that little attention was paid to drilling crucial reading skills for both careful and expeditious types of reading. 


\section{Current Approaches to Teaching Writing Skills}

\subsection{Overview of Saudi EFL Teachers'Approaches to Teaching Writing Skills}

The current practice of teaching writing skills in Saudi EFL classrooms focuses primarily on the final product of writing, and writing at the sentence level, alongside linguistic features, at the expense of teaching the skills needed to write coherent paragraphs (Al-Nufaie \& Grenfell, 2012; Vanderpyl, 2012; Al-Seghayer, 2017). In particular, Saudi teachers emphasize linguistic accuracy as well as proper grammar, accurate spelling, meaningful punctuation, and a wide range of variety in vocabulary and sentence structure. In this approach, Saudi teachers regard writing as an orderly sequence of discrete activities rather than a recursive process involving overlapping steps that effective writers have to go through in the writing process.

As is the case with instruction for the other three core language skills, the current practice in Saudi EFL classrooms reflects a traditional and product-based approach, that is, teacher-centered writing instruction with a product-oriented mode of writing (Al-Shammari, 2020; Al-Harth 2021). In this approach, Saudi teachers eliminate interactions between the teacher and students or among students and approach writing as a linear process in which students are expected to follow fixed steps, such as prewriting, writing, and rewriting, and to construct a rule-governed text.

At the same time, they do not teach students to edit or revise their work, meaning that students show little flexibility in regard to changing their original ideas. Overall, teachers focus more on what students produce than on how they produce their writing and the processes that they utilize. This represents what Saba (2015) referred to as the old familiar paradigm that views learning how to write in L2 as simply a means for learning how to produce an error-free final product whose correctness will be defined and enforced by the teacher.

This product-oriented approach often involves teachers simply providing guidance, assistance with questions that they asked, a model to follow (for example, students are introduced to a guided composition in the form of a preconstructed model of short pieces of writing), an outline to expand, an incomplete piece of writing to complete, or an incorrect text to correct. Teachers avoid other writing activities, such as reflections, free writing, journal writing, creative writing (in which students are required to draw on both their linguistic resources and their imaginations) and writing in silence. Additionally, they do not train students in specific purposes for writing such as arguments, narratives, and informative or explanatory texts. Furthermore, when setting a writing task, teachers tend to ask students to write without allowing them to plan or collect related information. They also neglect the benefits of teacher-student conferencing and peer feedback. Instead, students receive only authoritative written feedback and minimal commentaries on grammatical and vocabulary errors as well as punctuation marks and organization, which they then review in a subsequent class. Because students are expected to write specific, rule-governed texts, the actual task of providing feedback and correcting students' writing is overwhelming for teachers.

Overall, writing instruction in Saudi EFL classrooms overemphasizes the final written product and prioritizes the accuracy of linguistic forms, linearity, and prescriptivism. Teachers are concerned primarily with students' surface-level errors (grammatical, lexical, and mechanical features) rather than meaning-level errors and global issues such as logic, rhetoric, and ideas. Thus, the role of the teacher is that of a proof-reader and judge of the finished written work.

\subsection{Factors Underlying Current Saudi EFL Teachers' Approaches to Teaching Writing Skills in Saudi EFL Classrooms}

Various factors influence the prevalence of strict formats and traditional methods of writing instruction in Saudi EFL classrooms, including large or overcrowded classes and time constraints in which teachers are left with insufficient time to implement effective writing activities. Some teachers lack experience in teaching L2 writing and are not aware of appropriate theories of writing. As such, their focus is placed upon sentence structure, grammatical correctness, and spelling. Saudi EFL teachers also do not give adequate attention to the skill of writing and its components or to writing conventions including organization, ideas, content, voice, word choice, cohesive devise, logical relations between sentences, textual convention pertaining to paragraph structure, and proper ways of developing a paragraph as well as logical sequencing of ideas. Furthermore, they do not teach their students that writing is a means of creating and forming ideas. Moreover, some students lack the ability to write in their own language (i.e., Arabic) and adequate training in writing English. As a result, students demonstrate an inappropriate use of writing strategies and poor composing competence. Examining the relationship between Saudi students' English writing competence and their Arabic writing proficiency, Al-Samadani (2010) found that students who scored highly on Arabic essays received very similar scores on English essays and vice versa. Thus, Saudi students who develop a high proficiency in Arabic writing have a high likelihood of being good English 
writers. Saudi students tend to transfer the stylistic features of Arabic writing to English. They tend to write long or run-on sentences using the coordinating conjunctions " $a n d$ " and " $a$ " which are parallel to " $w a$ " and " $f a$ " in Arabic; excessively repeat themselves; and argue through presentation and elaboration (Al-Mehmadi, 2012). Since presentation and elaboration are features of argumentation in Arabic prose, Saudi students often talk around the topic and repeat phrases before stating the main points. Further cross-linguistic influences of L1 Arabic on ESL English writing also appear in their preference of the use of coordinate rather than subordinate words (Al-Samadani, 2010). Barry (2014) analyzed the writing samples of 38 Saudi students to investigate the influence of Arabic on English writing. The results revealed that the students used an excessive number of conjunctions, especially "and" in their English writing and an infinite number of commas in their English run-on sentences. This is because Arabic has fewer limitations in the use of commas and periods than English.

Additional factors that influence learning outcomes include insufficient writing practice, instructors who look for errors rather than ideas (as if the idea behind the writing is trivial), a lack of feedback on content, and a focus on only formal and grammatically correct sentences that follow the structural approach of error and contrastive analysis. Moreover, teachers do not train students to express themselves, reflect on their ideas, or formulate their critical thinking skills (Huwari \& Al-Khasawneh, 2013). It seems that teachers find it easier to focus on teaching at the micro-linguistic level, that is, the mechanics of writing, spelling, punctuation, and sentence structure rather than teaching at the macro-linguistic level, which aims to develop learners' discourse and pragmatic abilities in writing. The findings of Alkubaidi's (2019) study indicated that the instructional approach to teaching writing skills in Saudi English classrooms focuses on form and mechanics rather than communicative aspects of writing, purpose, and genre.

Teachers who emphasize surface-level errors lead students to passively copy the teacher's corrections into revisions without understanding how to identify and correct errors on their own (Alqurashi, 2015). Javid and Umer (2014) and Alharbi (2017) attributed these factors to the ineffective writing teaching methodology used in Saudi English classrooms. Furthermore, Al-Khairy (2013) noted that the prevalence of traditional methods of writing instruction in Saudi EFL classrooms stems from Saudi EFL learners being engaged only in sentence-level or, at the maximum, paragraph-level writing. Teachers continue to mistakenly believe that the acquisition of grammar is the key to mastering writing skills, and therefore, they rely heavily on a grammar-based approach to writing with a main focus on producing grammatically correct sentences free of spelling and punctuation mistakes rather than on the conveyance of students' ideas, opinions, information and other reasons for writing. The findings of Algonhaim's (2015) study showed that Saudi EFL learners also have a say in this. Only $48.1 \%$ of Saudi students surveyed reported that they liked to write English compositions, dialogues, letters, memos, summaries, and reports in class, whereas $65.4 \%$ reported that they liked written exercises that asked students to fill in the correct forms of verbs in sentences.

Another impediment to effective and efficient instructional writing in the Saudi EFL classroom is that teachers use inappropriate teaching methods and lack interest in assigning writing tasks. They also lack the proper motivation to engage in teaching the writing process and do not process the willingness to incorporate innovation and modern techniques into their teaching practices to help students produce coherent paragraphs and varied sentence structures that help to enrich their writing, retain the reader's interest, and clarify their intended meanings. Furthermore, teachers do not train students to express themselves, to generate ideas and reflect on them, or to formulate critical as well as creative thinking skills, and they do not encourage students to reflect on how they organize ideas, facts, and details (Huwari \& Al-Khasawneh, 2013).

With respect to the writing process, Saudi teachers do not engage students in using cyclical stages to draft their writing tasks, receive feedback from peers or the teacher and give feedback to peers, or further revise their evolving texts. Instead, students are introduced only to guided compositions in the form of preconstructed models of short pieces of writing, which they are required to memorize for tests (Saba, 2015). Teachers also avoid implementing pattern-model-based writing, which is used to teach students various skills and forms of writing (e.g., the topic sentence and rhetorical modes, such as comparison and contrast or cause and effect in short paragraphs). Moreover, students do not receive training in formal or academic writing or in developing original ideas through writing or discussion as well as developing ideas in a manner that conforms to the conventions of writing in English.

Al-Mukhaizeem (2013) and Ankawi (2015) further noted that Saudi students do not practice writing regularly and that opportunities to practice writing in the classroom are insufficient. Students' inadequate writing performance is ascribed to the decisive factor of lacking practice and guidance in writing skills. In addition, teachers tend to neglect some aspects of writing mechanics as well as the process of planning. They also fail to provide adequate feedback concerning the writing process, cohesion, and organization (Shukri, 2014). Accordingly, Saudi EFL 
students are not properly trained in writing and exhibit an immature mastery of the rhetorical structure of English texts.

\section{Current Approaches to Teaching Vocabulary}

\subsection{Overview of Saudi EFL Teachers' Approaches to Teaching Vocabulary Practices}

Regarding English vocabulary instructional practices, Saudi EFL teachers typically adopt traditional and direct vocabulary-teaching techniques that feature the presentation, production and practice (PPP) methodology. Examples of mundane techniques include having students (a) match words to their definitions, (b) fill in blanks with suitable words, (c) look up dictionary definitions, (d) copy definitions, (e) write sentences for each word based on its definition, (f) write the L2 word along with its L1 definition or translation, and (g) memorize word lists. Oxford and Scarcella (1994) categorized these traditional vocabulary drills and techniques as decontextualized activities that do not entail active engagement or go beyond definition knowledge. Accordingly, such activities fail to improve students' ability to notice and learn unknown words independently and incidentally. Altyari (2017) contended that the low vocabulary uptake by Saudi EFL leaners is mainly attributed to the current ineffective vocabulary teaching methodology which is non-incremental. Saudi EFL teachers merely establish the form-meaning links by giving direct translations and do not provide their students with opportunity to learn all the different types of word knowledge.

In general, Saudi EFL teachers present vocabulary items in controlled, decontextualized tasks, such as in word lists, flash cards, and dictionary look-up activities, as well as during study situations that lack communicative value. In these unplanned and unsystematic vocabulary-teaching activities, students ask for the meanings of unknown vocabulary items and teachers provide those meanings. Teachers might also ask students to write one-word answers to questions that should require complete sentences. Alqahtani (2009) and Afzal (2019) described such practices as unproductive. Similarly, Al-Mohanna (2010) indicated that vocabulary instruction merely engages students in copying vocabulary items into their notebooks and performing various word-matching exercises. Although teachers devote a considerable amount of instructional time to explaining and defining terms, this approach to vocabulary instruction is haphazard and fails to relate vocabulary learning to the students' real lives or interests. In the current practice, vocabulary is taught neither explicitly nor systematically in Saudi English EFL classrooms; teachers merely provide students with word lists to memorize. In Al-Zahrani's (2011) study, such ineffective vocabulary instruction led to low vocabulary achievement among Saudi EFL students via teachers introducing words in lists rather than in context, students learning vocabulary by rote, and teachers asking students to write one-word answers to questions that required complete sentences.

Overall, actual vocabulary instruction in Saudi EFL classrooms does not consider goals or employ precise teaching techniques, vocabulary learning strategies, or varied planned vocabulary presentations. Instead, this instruction focuses primarily on abstract explaining, simple exercises, and rote learning.

\subsection{Factors Underlying Current Saudi EFL Teachers' Approaches to Teaching Vocabulary in Saudi EFL Classrooms}

English classrooms in Saudi Arabia demonstrate insufficient consideration of the challenges of English vocabulary acquisition. Saudi EFL teachers believe in the notion of autonomous vocabulary learning strategies and that vocabulary growth will happen automatically when students are engaged in reading various texts or using other language skills. Accordingly, Saudi teachers expect students to acquire target vocabulary items on their own without much guidance or explicit strategy instruction (Al-Harthi, 2015). They also neglect to provide opportunities to learn vocabulary through context or help students learn specific strategies for acquiring words at each stage of the learning process, which comprises encountering new words, identifying word forms, determining meanings, consolidating word forms, accessing meanings in memory, finding contextual information, performing rote rehearsal, encoding (such as word formation), and using words in writing and speech.

Therefore, current vocabulary teaching is limited to elementary levels by presenting new vocabulary items as they appear in readings or listening, which is indicative of the indirect teaching of vocabulary and a lack of direct exposure to words in a variety of language contexts. In other words, teachers do not provide meaningful tools or applications that sustain engagement, enrich learning, and empower students during vocabulary-building activities. Abdalla (2015) found additional related vocabulary instructional practices in Saudi English classrooms. About $78 \%$ of the 50 surveyed English teachers admitted that they used traditional vocabulary-teaching methods and that these ineffective teaching methods hindered Saudi students from using the acquired vocabulary effectively. Additionally, $76 \%$ of the English teachers indicated that they provided the meanings of target vocabulary items in Arabic. Abdalla stated that teachers' negligence in illustrating some crucial aspects of 
vocabulary knowledge (word polysemy, homonymy, connotation, word basic parts of speech, synonymy, and antonymy) is a major cause of students' inefficient use of English vocabulary.

Teachers also do not implement related L2 vocabulary instructional practices that promote vocabulary development and retention, nor do they use teaching approaches that incorporate cognitive and metacognitive strategies. For example, in a study of 200 Saudi EFL students at four educational levels, Albousaif (2011) found that Saudi teachers did not provide specific class time for teaching dictionary skills or encourage students to use dictionary features such as definitions, parts of speech, synonyms, antonyms, pictures, or examples that would demonstrate how to use words in different contexts. These teachers also did not train their students on using online dictionaries or mobile dictionary applications effectively. Moreover, the teachers neglected to provide effective strategies for learning new vocabulary items, such as mnemonic techniques, identifying the parts of speech and constituent elements, deriving the meanings of unfamiliar words from context, looking for available clues in the text, or using other vocabulary-building strategies that would lead to successful acquisition of English vocabulary. Bahanshal (2015) also found that Saudi teachers fail to teach such strategies and refrain from developing challenging activities and intensive practices that would encourage students to experiment with L2 vocabulary-learning strategies in meaningful contexts. Instead, the teachers present new items as they appear in reading or in listening and simply ask students to copy down new words listed on the board. As Albousaif contended, this strategy - that is, listing new words on the board and then asking students to copy them-does not guarantee vocabulary acquisition or growth and development of students' English vocabulary.

Given this prevalence of ineffective vocabulary-teaching strategies, Al-Gahtani (2015) argued that Saudi EFL teachers are not confident about the best practices in vocabulary teaching and, at times, do not know where to begin to form an instructional to emphasize learning words during instruction. Furthermore, because they are unequipped to handle this pedagogical task, they have problems knowing how to teach students to gain satisfactory results. Overall, Saudi EFL teachers' vocabulary instruction fails to resolve three major issues that draw on research-based principles of vocabulary instruction in classroom teaching: (a) how to learn vocabulary (vocabulary-learning strategies), (b) what to teach about vocabulary (learning goals), and (c) how to teach vocabulary (teaching techniques). This unimplemented vocabulary instruction can be summarized as strategies for discovering the meaning of unknown words, retaining the newly learned words in long-term memory, and recalling them at will.

Another contributing factor to insufficient English vocabulary instruction in Saudi Arabia is that many Saudi EFL teachers are not trying hard enough to help their students become autonomous vocabulary learners who can acquire vocabulary on their own through independent and self-directed lexical processing and learning.

Al-Harthi (2015) indicated that Saudi EFL learners are left to struggle to pick up lexical knowledge without necessary guidance. Teachers are not providing their students with meaningful tools and applications that sustain engagement, enrich learning, and empower students during vocabulary-building activities. In the same vein, Al-Haysony (2012) pointed out that students in Saudi Arabia mainly rely on teachers or someone else when learning basic information about new English words rather than trying alternative strategies themselves.

\section{Current Approaches to Teaching Grammar}

\subsection{Overview of Saudi EFL Teachers' Approaches to Teaching Grammar in Saudi English Classrooms}

With respect to the status quo of grammar instruction, a traditional or outmoded approach dominates the actual grammar instructional practices in Saudi EFL classrooms, namely the presentation-practice-production (PPP) model, which is akin to a rule-driven deductive approach. This model views grammar as a product that entails dividing language into segments and teaching those segments independently of one another.

Using the PPP model, Saudi EFL teachers present a language structure or tense (e.g., present simple) and have students practice using it. For example, the teacher may introduce a new concept directly by writing a full explanation of the grammatical structure on the board and by discussing the examples provided in the textbook. The students then practice the newly introduced grammatical rule by completing highly controlled practical exercises, including fill-in-the-blank and mechanical drill activities (e.g., transformation, substitution, and integration drills). Ultimately, the students produce an example of what they have learned, in which case the teacher may ask students to generate their own examples and share them with the class or to simply copy the rule together with examples into their notebooks.

Such a form-focused approach to teaching grammar encourages grammatical correctness and considers knowledge of grammar as the end goal (Assalahi, 2013). The teaching methods used in the approach likewise aim to provide students with a detailed analysis of the rules of English grammar, typically with an emphasis on 
accuracy (Zohairy, 2015). As such, the approach adopts an overt, explicit presentation of independent grammatical rules and prioritizes teaching grammar in isolation, memorizing rules and terminology, and, in general, spoon-feeding knowledge over exploring it (Al-Balawi, 2014). As a result, Saudi EFL learners lack sufficient opportunities to practice the English language, and advanced application-oriented grammar remains virtually untaught.

The approach's focus on structural or descriptive grammar excludes models of functional grammar (i.e., functions performed by grammatical forms) and generative grammar based on the theory of universal grammar. Furthermore, grammar is rarely taught communicatively (Al-Musharraf, 2007). In fact, Saudi EFL teachers teach grammar independent of other related language skills, such as reading and writing. By failing to contextualize input in the sense of encouraging the synergistic development of skills, teachers reduce students' communicative competence (Ahmad, 2014).

Overall, Saudi EFL teachers (a) teach grammatical concepts using many isolated examples that are not contextualized or involved in communicative tasks; (b) stress the mastery of grammatical concepts under study; (c) place limited emphasis on practice; (d) refrain from incorporating the studied rules of grammar into other language skills; (e) use Arabic, as the L1, to simplify the rules for students and to facilitate the learning of grammar; and (f) focus on grammatical correctness and/or the accuracy of production.

\subsection{Underlying Factors Behind Saudi EFL Teachers' Approaches to Teaching Grammar in Saudi EFL Classrooms}

Myriad factors influence current pedagogical practices employed in grammar instruction in Saudi EFL classrooms. According to Al-Johani (2012), Saudi EFL teachers favor a form-focused approach over meaning-focused instruction and thus fail to provide immediate corrective feedback, whether spoken or written, to their students during integrated communicative activities. The focus on form not only assumes that language consists of grammatical forms that can be acquired sequentially and additively but also overtly draws students' attention to linguistic elements as they arise incidentally in lessons. By contrast, meaning-focused instruction proposes that students learn the language and understand its grammar inductively.

Accordingly, instead of creating the conditions in which their students could learn grammar naturally or through reflection and discovery, which would entail granting students a decisive role in the learning process, Saudi EFL teachers focus on teaching discrete grammatical structures explicitly. In the process, they do not expose students to input that provides multiple examples of the grammatical concepts being studied. However, Saudi learners' preference for a deductive or rule-driven approach appears to influence the teachers' pedagogical choices regarding explicit versus contextual grammar instruction (Al-Balawi, 2014).

Grammar instruction is also more mechanical in nature than interactional in Saudi EFL classrooms. In particular, Al-Ghanmi and Shukri (2016) found that Saudi teachers prefer to use traditional techniques of translating grammar and audio-lingual method including drilling, memorizing grammar rules, and using the L1. Thus, Saudi EFL students do not engage in sufficient learning activities and do not receive ample time to practice and produce in practical ways the grammatical features that they have studied. Instead, students work with grammar rules in controlled, mechanical activities that chiefly focus on form, which places students in the position of simply receiving rules instead of putting them into practice. As a result, students can often successfully perform tasks without truly understanding the language that they are using.

Another source of difficulty is that Saudi EFL teachers do not demonstrate the utility of grammar in real contexts. As Al-Ghanmi and Shukri (2016) have argued, Saudi grammar instruction involves direct instruction with a focus on accuracy, not fluency, and teaching grammar in isolation instead of exposing students to the ways in which grammar is used in context. In that light, teachers regard grammar as a somewhat isolated collection of rules that exist independently of their appropriate use in real-world texts, whether written or spoken. Furthermore, due to the current orientation of EFL instruction in Saudi classrooms, some teachers provide grammar instruction using an exam-oriented approach instead of a notional-functional approach. In an exam-oriented approach, the teacher's primary task is to prepare students for tests that measure grammatical accuracy only. Because their ultimate learning goal is to achieve good grades, students memorize grammatical rules only to pass the exam. Thus, students divert all of their energy to that purpose and pay little attention to true learning (Shah et al., 2013).

The prevalence of such outdated methods in the Saudi EFL classrooms demonstrate that the teachers lack awareness of competence-based grammar instruction - rather than performance-based-grammar instruction. These teachers are not completely aware of the distinction between grammatical knowledge and grammatical ability that is central to grammar pedagogy; and therefore, fail to incorporate both competence- and 
performance-based strategies into their teaching. Instead, they mostly aim to enhance students' knowledge of English grammatical features at the expense of improving their ability to use select grammar structures accurately in meaningful spoken and written communication. Al-Muhammadi (2020) investigated the beliefs of 55 Saudi EFL teachers regarding the use of various teaching approaches for teaching grammar and found that teachers still need to develop practical skills for grammar instruction.

Finally, Saudi EFL teachers do not redeploy their students' grammatical errors to supplement grammar instruction. In particular, they do not develop classroom activities focused on the specific errors that students often make, and they also fail to address errors that arise in ongoing work in the classroom.

\section{Current Approaches to Teaching Cultural Knowledge}

\subsection{Overview of Saudi EFL Teachers' Approaches to Teaching Cultural Knowledge in Saudi EFL Classrooms}

Cultural awareness, as a severely neglected feature of the Saudi English curriculum is an aspect of the country's null curriculum - that is, what the curriculum does not teach or unintentionally omits. To be more precise, though language and culture are inextricably linked such that the very words that speakers use are filtered by culture, culture is hardly taught in the Saudi EFL classroom and is not embedded in materials for language instruction. Likewise, no courses in the curriculum explicitly focus on developing awareness of cultural specifics (e.g., values, norms, and beliefs) or general cultural skills (e.g., intercultural communication and understanding) in the Saudi EFL curriculum. Added to that, Saudi EFL teachers do not present cultural information, model cultural behaviors, guide cultural research and analysis, or develop their students' cultural awareness. As noted by Uddin (2017), they also exclude elements from their teaching such as when and what people in L2-speaking populations eat, how they earn a living, the attitudes that they use to show approval and disapproval, their attitudes toward education, their work values, and the culture's common spatiotemporal patterns.

According to Liton (2012), the sociocultural spirit of English-speaking countries is not well coordinated with the Saudi English curriculum. Thus, instead of discussing the Western cultural values in which the English language is rooted, Saudi teachers teach English with greater reference to local Saudi cultural models (Al-Fahad, 2012). Furthermore, Saudi teachers believe that religious values are integral to cultural practice; thus, classroom activities draw heavily on cultural values that are embedded in Islam. According to Uddin (2017), some teachers strongly believe that teaching English should be independent of its nationality-bound cultural context. They and other Saudi teachers are also liable to believe in the principle of language first, culture later - that is, that students should first master the basic grammatical structures and lexical features that form the language's foundation before being exposed to the cultures of English-speaking people.

In EFL instruction in Saudi Arabia, a mismatch also exists between the stated goals of EFL education, and the means used to achieve them. For instance, a stated goal of Saudi EFL is to prepare Saudi citizens to become intercultural speakers or cross-cultural literates who are knowledgeable of different cultural practices and worldviews. However, current teaching practices do nothing to pursue or reinforce that goal. Additionally, references to and activities associated with the cultures of native English speakers are rarely found in Saudi English textbooks, and guidelines or policies, if any, on how to introduce English culture or the cultures of English-speaking nations into EFL classrooms remain unclear (Al-Seghayer, 2015).

Despite such neglect, cultural awareness ranks among the five major factors constituting language competence and significantly helps students studying a foreign language to achieve success in the language-learning process. In that context, cultural awareness encompasses cultural knowledge, cultural understanding, and awareness and competence in cross-cultural communication. Unfortunately, although Saudi teachers acknowledge the importance of teaching culture with EFL in that learning a language and learning about culture are mutually reinforcing, culture does not occupy an explicit place in Saudi EFL instruction, and no courses in the curriculum focus on developing cultural awareness in the Saudi EFL curriculum.

\subsection{Underlying Factors Behind Current Saudi EFL Teachers' Approaches to Teaching Cultural Knowledge in Saudi EFL Classrooms}

A range of complex factors contribute to the reason why Saudi EFL teachers do not address culture in their EFL teaching practices. For example, some EFL teachers perceive teaching cultural values as a form of cultural imposition or, more accurately, as a form of linguistic globalization emanating from cultural globalization. Teachers who view instruction in culture as a covert way of imposing cultural hegemony or linguistic imperialism fear that teaching Western values or Anglo-American cultural practices is liable to alienate students from their own cultural values and erode their identities owing to the non-representation of their own context (Al-Dosari, 2013; Al-Samani, 2014; Al-Seghayer, 2016; Aldera, 2017). Some teachers also believe that teaching non-local culture 
may diminish students' motivation or, worse still, encourage them to adopt cultural values associated with the English language. As a consequence, Saudi EFL teachers do not present cultural information, model cultural behaviors, guide cultural research or analysis, or develop their students' cultural awareness.

Regarding culture in EFL textbooks used in Saudi Arabia, Al-Harbi (2015) evaluated the perspectives of Saudi EFL teachers on the English textbook Flying High for Saudi Arabia. According to Aldhabi, the participants expressed dissatisfaction with the inclusion of more English cultural elements than Saudi elements. Similarly, Al-Shammari (2015) noted that "English courses are based almost entirely on U.S. textbooks, which typically do not give any consideration to the Arabic or Islamic culture, and contrast sharply with the traditions and values of the Saudi lifestyle" (p. 367). Because of the perceived incompatibility of Western values and norms with local and Islamic culture, many Saudi individuals have called for including only Islamic and local cultural values in EFL textbooks (Al-Seghayer, 2011, 2016). In the same vein, Al-Mujaiwel (2018) investigated the extent to which EFL textbooks in Saudi Arabia integrate cultural aspects, represented by words associated with 20 selected cultural topics (i.e., climate, clothing, eating, education, family life, geography, history, holidays, humor, language, leisure, meeting people, currency, pets, population, religions, social occasions, sports, transportation, and vacations). The findings showed that in Saudi English textbooks present local Arabic cultural words more frequently than target English cultural words and the latter more frequently than intercultural words. In other work, drawing from personal experience, Al-Amri (2019) recounted more than four years of working as an EFL teacher in Saudi Arabia, both under the old and new curricula of the Saudi EFL education system, in which he taught EFL but with primary reference to Saudi culture. The reason for that approach was because the majority of content in the textbooks focused on Saudi and Islamic culture, whereas only a few pages represented the cultural values of speakers of the target language.

A lack of time, resources, and knowledge also hinder the efforts of Saudi EFL teachers' efforts to teach culture effectively. Concerning time, as was previously noted, Saudi EFL teachers teach an overcrowded curriculum within a severely limited period; for them, teaching culture thus requires additional time that they simply do not have. Concerning resources, the teachers lack practical techniques and follow impractical syllabi that exclude cultural knowledge from all forms of assessment. Finally, concerning knowledge, they lack an adequate cultural understanding on which to base their instruction. Some Saudi English teachers view English culture as a homogeneous culture and U.S. culture as representative of Western culture. In this case, they either do not know or ignore the fact that many different English-speaking countries with a variety of English cultures exist.

Saudi Arabia's current English-teacher training program also fails to prepare Saudi EFL teachers to teach culture effectively. Saudi teachers cannot manage to incorporate meaningful cultural knowledge into the EFL classroom because they lack training in theories related to teaching culture and in using models that promote intercultural competence and view culture as an integral component of language learning. Put differently, they lack a suitable framework for defining culture as well as guidelines for incorporating culture into EFL classrooms. They also have limited access to training or workshops that would keep them abreast of the latest trends in techniques for teaching culture and raising their students' awareness of cultural differences. Moreover, few Saudi EFL teachers have lived in English-speaking countries, which, paired with the unavailability of sufficient culturally oriented materials, has precluded them from obtaining appropriate, useful information about the cultures of English-speaking people. Accordingly, Saudi EFL teachers are ill-prepared to help their students to learn to use English in a culturally appropriate manner.

Finally, the attitudes of Saudi EFL teachers also contribute to their failure to teach culture in any Saudi EFL classes at all levels of public education. As previously discussed, for those teachers, full mastery of EFL means understanding the rules and using the four language skills flawlessly. Thus, many Saudi teachers believe in the above-described principle of language first, culture later. Related to that issue, Al-Amri (2019) explored the perspectives of selected Saudi EFL teachers and stakeholders concerning the integration of materials with relevant cultural contents into Saudi EFL textbooks. Findings revealed that both teachers and stakeholders were reluctant to incorporate cultural elements because of geopolitically sensitive contexts and the impact of the cultural content and values of English-speaking countries entirely different from their own on their culture and identity.

\section{Conclusion}

This comprehensive account details the instructional practices currently being used in Saudi EFL classrooms as well as some prominent pedagogical factors underlying current Saudi EFL teachers' approaches to teaching the four macro and micro language skills. The discussion delineates how the current Saudi pedagogical practices used to teach EFL are ineffective and do not reflect the prominent status of English in 21st-century Saudi Arabia. 
Furthermore, it illustrates the incompatibility of current practices with the current language demands in Saudi Arabia. Therefore, without new, effective pedagogical techniques and methods to follow, it will not be possible to change Saudi EFL teachers' approaches. Saudi EFL teachers should strive to minimize the effect of factors that adversely influence the teaching process in Saudi EFL classrooms. Swift and decisive measures are required to transform pedagogical practices, particularly to promote communicative language teaching and renounce or shift from outmoded language-teaching methods.

\section{References}

Abdalla, A. (2015). Promoting lexical knowledge in the Saudi tertiary EFL classroom at Taif University. International Journal of Social Science and Humanities Research, 3(3), 86-92.

Abu-Ghararah, B. (2014). Problems with speaking activities in the Saudi EFL classroom. Arab World English Journal, 5(4), 276-287.

Afzal, N. (2019). A study on vocabulary-learning problems encountered by BA English majors at the university level of education. Arab World English Journal, 10(3), 81-98. https://doi.org/10.24093/awej/vol10no3.6

Al-Abiky, W. (2014). Assessment of Reading Comprehension of Saudi Students Majoring in English at Qassim University, Saudi Arabia. Studies in Literature and Language, 9(1) 155-162.

Al-Amri, B. (2019). Foreign culture in English curriculum in Saudi Arabia: A teacher's voice. Arab World English Journal, Special Issue 1: Application of Global ELT Practices in Saudi Arabia, 34-41. https://doi.org/10.24093/awej/elt1.3

Al-Balawi, S. (2014). Using media to teach grammar in context and UNESCO values: A case study of two English teachers and students from Saudi Arabia. Unpublished master's thesis. Eastern Washington University, Cheney, WA.

Al-Bargi, A. (2013). Listening in beginner language courses: The gathering storm in the Saudi context. Life Science Journal, 10(4), 3580-3584.

Al-Dosari, H. (2013). Integrating culture learning into foreign language education. Umm Al-Qurma University Journal of Languages and Literature, 11, 10-42.

Al-Fahad, A. (2012). Saudi teachers' view on the appropriate cultural model for EFL textbooks: Insights into TESOL teachers' management of global cultural flows and local realties in their teaching world. Unpublished doctoral dissertation. University of Exeter, Exeter, United Kingdom.

Al-Ghanmi, B., \& Shukri, N. (2016). The relationship between teachers' beliefs of grammar instruction and classroom practices in the Saudi context. English Language Teaching, 9(7), 70-86.

Al-Hamdan, B. (2014). A discursive lens on English language teaching and learning in Saudi Arabia. Unpublished doctoral dissertation. The University of Queensland, Brisbane, Australia.

Al-Harbi, A. (2015). A descriptive-evaluative study of a Saudi EFL textbook series. Cogent Education, 2(1), $2-26$.

Al-Harbi, H. (2015). Improving students' English-speaking proficiency in Saudi public schools. International Journal of Instruction, 8(1), 105-116.

Al-Harth, S. (2021). From instructed writing to free-writing: A study of EFL learners. SAGE Open, 11(1), 1-15.

Al-Harthi, T. (2015). Reasons for vocabulary attrition: Revisiting the state of the art. International Education Studies, 8(10), 86-95.

Al-Haysony, M. (2012). Vocabulary discovery strategy used by Saudi EFL students in an intensive English language learning context. International Journal of Linguistics, 4(2), 518-535.

Al-Johani, M. (2012). Grammar Beliefs of in-Service Teachers. British Journal of Arts and Social Sciences, 11(1), 96-108.

Al-Ma'shy, A. (2011). Causes of EFL speaking weakness in Saudi secondary schools in Al-Gunfuthah City. Unpublished master's thesis. King Saudi University, Riyadh, Saudi Arabia.

Al-Malki, M. (2014). Teacher perception of a new English as a foreign language (EFL) curriculum in Saudi Arabia. Unpublished master's thesis. State University of New York at Fredonia, Fredonia, NY.

Al-Mehmadi, M. M. (2012). A contrastive rhetorical analysis of factual texts in English and Arabic. Frontiers of Language and Teaching, 3, 68-76. 
Al-Mohanna, A. (2010). English teaching in Saudi Arabian context: How communicatively oriented is it? Journal of King Saudi University (Language and Translation), 22(1), 69-88.

Al-Muhammadi, A. (2020). Teaching grammar: professional needs of Saudi EFL instructors. International Journal of English Linguistics, 10(3), 14-20.

Al-Mujaiwel, S. (2018). Analysing culture and interculture in Saudi EFL textbooks: A corpus linguistic approach. English Language Teaching, 11(2), 31-43.

Al-Mukhaizeem, Y. (2013). Investigating students' ability in handling problems in writing mechanics at King Saud University. International Journal of Linguistics, 5(6), 22-36.

Al-Nooh, A. (2013). The effectiveness of reading techniques used in a Saudi Arabian secondary school classroom as perceived by students and teachers: A study of methods used in teaching English and their effectiveness. Arab World English Journal, 4(3), 331-345.

Al-Nufaie, M., \& Grenfell, M. (2012). EFL students' writing strategies in Saudi Arabian ESP writing classes: Perspectives on learning strategies in self-access language learning. Studies in Self-Access Learning Journal, $3(4), 407-422$.

Al-Qahtani, A. (2016). Why do Saudi EFL readers exhibit poor reading abilities? English Language and Literature Studies, 6(1), 1-15.

Al-Rabai, F. (2014). A model of foreign language anxiety in the Saudi EFL context. English Language Teaching, $7(7), 82-101$.

Al-Rojaie, Y. (2011). Saudi EFL reading teachers' pedagogical beliefs and practices: A qualitative case study. Journal of Arabic and Human Sciences, 5(1), 1-19.

Al-Samadani, H. (2010). The relationship between Saudi EFL students' writing competence, L1 writing proficiency, and self-regulation. European Journal of Social Sciences, 16(1), 53-63.

Al-Samadani, H. (2011). Saudi students' awareness of reading strategies and factors affecting their EFL reading comprehension. British Journal of Arts and Social Sciences, 2(2), 75-87.

Al-Samadani, H. (2012). Reading strategy instruction in Saudi schools. Journal of Language Teaching and Research, 3(5), 829-837.

Al-Samani, A. (2014). Foreign culture awareness needs of Saudi English language majors at Buraydah Community College. English Language Teaching, 7(6), 143-153.

Al-Saraj, M. (2014). Foreign language anxiety in female Arabs learning English: Case studies. Innovation in Language Learning and Teaching, 8(3), 257-278.

Al-Seghayer, K. (2011). English teaching in Saudi Arabia: Status, issues, and challenges. Riyadh, Saudi Arabia: Hala Printed.

Al-Seghayer, K. (2015). Salient key features of actual English instructional practices in Saudi Arabia. English Language Teaching, 8(6), 89-99.

Al-Seghayer, K. (2016). Real Face of Saudi Arabia: Critical Insider Perspectives on Educational, Lifestyle, and Social Issues in the Kingdom. Riyadh, Saudi Arabia: Hala Printed Co.

Al-Seghayer, K. (2017). Reality and Challenges of TEFL in 21st-Century Saudi Araba. Saudi Arabia: Hala Printed Co.

Al-Seghayer, K. (2019). Unique challenges Saudi EFL Learners Face. Studies in English Language Teaching, $7(4), 490-515$.

Al-Shabeeh, F. (2104). Assessing oral proficiency in large EFL classroom in Saudi Arabia. Unpublished master's thesis. University of Oregon, Eugene, OR.

Al-Shammari, A. (2015). Developing the English curriculum in the Kingdom of Saudi Arabia: Possibilities and challenges. Arab World English Journal, 6(4), 365-372.

Al-Shammari, S. (2020). Writing to learn or learning to write. A critical review of English as a foreign language (EFL) teaching practices in writing in Saudi universities. Research in Education and Learning Innovation Archives, 24, 1-22. https://doi.org/10.7203/realia.24.15867

Al-Shumaimeri, Y. (2011). The effects of reading method on the comprehension performance of Saudi EFL students. International Electronic Journal of Elementary Education, 4(1),185-195. 
Al-Sobhi, B., \& Preece, A. (2018). Teaching English speaking skills to the Arab students in the Saudi school in Kuala Lumpur: Problems and solutions. International Journal of Education and Literacy Studies, 6(1), $1-11$.

Al-Subaie, M. (2014). An exploration of reading comprehension challenges in Saudi Arabian University EFL students. Unpublished doctoral dissertation. The University of Exeter, Exeter, United Kingdom.

Al-Zahrani, M. (2011). The effectiveness of keyword-based instruction in enhancing English vocabulary achievement and retention of intermediate stage pupils with different working memories capacities. Unpublished master's thesis. Taif University, Taif, Saudi Arabia.

Al-Zahrani, M., \& Al-Bargi, A. (2017). The impact of teacher questioning on creating interaction in EFL: A discourse analysis. English Language Teaching, 10(6),135-150.

Albousaif, M. (2011). Factors determining Saudi learners' difficulties in attaining EFL vocabulary. Unpublished doctoral dissertation. University of Newcastle, Newcastle, Australia.

Aldera, A, (2017). Teaching EFL in Saudi Arabian context: textbooks and culture. Journal of Language Teaching and Research, 8(2), 221-228.

Alkubaidi, M. (2019). An Action Research on EFL writing dilemmas: A case of Saudi students and instructors. Arab World English Journal, 10(3), 151-164. https://doi.org/10.24093/awej/vol10no3.10

Alsowat, H. (2017). A Systematic Review of Research on Teaching English Language Skills for Saudi EFL Students. Advances in Language and Literary Studies, 8(5), 30-45.

Altyari, A. (2017). English vocabulary uptake by Saudi Arabic-speaking students at public School. British Journal of English Linguistics, 5(1), 10-16.

Ankawi, A. (2015). The academic writing, challenges faced by Saudi students studying in New Zealand. Unpublished master's thesis. Auckland University of Technology, Auckland, New Zealand.

Assalahi, H. (2013). Why is the grammar-translation method still alive in the Arab world? Teachers' beliefs and its implications for EFL teacher education. Theory and Practice in Language Studies, 3(4), 589-599.

Bahanshal, D. (2015). The effectiveness of vocabulary learning strategies on English language acquisition of the Saudi learners. International Journal of Humanities and Social Sciences, 1(1), 47-56.

Bamanger, E., \& Gashan, A. (2014). In-service EFL teachers' beliefs about teaching reading strategies. English Language Teaching, 7(8), 14-22.

Bani Younes, Z., \& Albalawi, F. (2016). Investigating the factors leading to speaking difficulties: Both perspectives of EFL Saudi learners and their teachers. Arab World English Journal, 7(2), 268-287. https://doi.org/10.24093/awej/vol7no2.18

Bano, F. (2017). Towards understanding listening comprehension in EFL classroom: The case of the Saudi learners. English Language Teaching, 10(6), 21-27.

Barry, D. (2014). Impact of native Arabic on English writing as a second language. Clarkston, MI: Create Space Independent Publishing Platform.

Hamouda, A. (2013). An investigation of listening comprehension problems encountered by Saudi students in the EL listening classroom. International Journal of Academic Research in Progressive Education and Development, 2(2), 113-155.

Hazaea, A., \& Alzubi, A. (2016). The effectiveness of using mobile on EFL learners' reading practices in Najran University. English Language Teaching, 9(5), 8-21.

Huwari, I., \& Al-Khasawneh, F. (2013). The reasons behind the weaknesses of writing in English among pre-year students' at Taibah University. English for Specific Purposes World, 38(14), 1-9.

Jamal, M., Anas, A., \& Koka, N. (2020). Perception of Saudi EFL learners and teachers towards the use of listening transcript in the listening lessons. Arab World English Journal, 11(1), 297-314. https://doi.org/10.24093/awej/vol11no1.22

Kashmiri, H. (2019). Communication challenges: Saudi EFL Speaking Skills and strategies to overcome speaking difficulties. Unpublished M. A. master's thesis, Taif, Saudi Arabia.

Keezhatta, M., \& Omar, A. (2019). Enhancing reading skills for Saudi secondary school students through mobile assisted language learning (MALL): An experimental study. International Journal of English Linguistics, 
9(1), 437-447. https://doi.org/10.5539/ijel.v9n1p437

Liton, H. (2012). Developing EFL teaching and learning practices in Saudi colleges: A review. International Journal of Instruction, 5(2), 129-152.

Masadeh, T. (2015). Performance of Saudi English language teachers in reading comprehension classes. SAGE Open, 1-10. https://doi.org/10.1177/2158244015621598

Mohamed, M. (2018). Using audiobooks for developing listening comprehension among Saudi EFL preparatory year students. Journal of Language Teaching and Research, 9(1), 64-73. https://doi.org/10.17507/jltr.0901.08

Naser, I., \& Hamzah, M. (2018). Pronunciation and conversation challenges among Saudi EFL students. Journal of English Educators Society, 3(1), 85-104.

Nather, E. (2014). An integrated program to promote the confidence of Saudi public school students in speaking English. Unpublished doctoral dissertation. University of Canberra, Canberra, Australia.

Nurul Islam, M. (2012). An analysis on how to improve tertiary EFL students' listening skill of English. Journal of Studies in Education, 2(2), 205-214.

Panduranga, S. (2016). Teaching Listening Skills in an EFL Classroom - Building Activities. Rep Opinion, 8(11), $59-70$.

Rajab, H., \& Al-Sadi, A. (2015). An empirical study of reading habits and interests of Saudi university EFL learners. International Journal of Linguistics, 7(2), 1-17.

Saba, M. (2015). Saudi students' perception of peers' authority. Arab World English Journal, 6(2), 66-79.

Shah, S., Hussain, M., \& Nassef, O. (2013). Factors impacting EFL Teaching: An exploratory study in the Saudi Arabian context. Arab World English Journal, 4(3), 104-123.

Sharma, V. (2015). How do productive skills of Saudi students affect EFL learning and teaching. Asian Journal of Humanities and Social Sciences, 3(2), 91-99.

Shukri, A. (2014). Second language writing and culture: Issues and challenges from the Saudi learners' perspective. Arab World English Journal, 3(5), 190-207.

Uddin, N. (2017). Culture in teaching EFL in Saudi Arabia from learners' perspective. Journal of Arts \& Humanities, 6(3), 8-17.

Vanderpyl, G. (2012). The process approach as writing instruction in EFL (English as a Foreign Language) classrooms. Unpublished master's thesis. SIT Graduate Institute, Brattleboro, VT.

Zohairy, S. (2015). Applying DDL approach in teaching grammar interactively. Retrieved from https://www.academia.edu/8234438/Applying_DDL_Approach_in_Teaching_Grammar_Interactively

\section{Copyrights}

Copyright for this article is retained by the author, with first publication rights granted to the journal.

This is an open-access article distributed under the terms and conditions of the Creative Commons Attribution license (http://creativecommons.org/licenses/by/4.0/). 